\title{
The effect of aloe Vera gel, olive oil and wax on some quantitative and qualitative attributes of Kinnow tangerine in cold store
}

\author{
Mohammad Reza Kalantari ${ }^{1}$ and Majid Rahemi ${ }^{2}$ \\ ${ }^{I}$ PhD student, Islamic Azad University, Science and Research Branch, Tehran \\ ${ }^{2}$ Professor of Agriculture department, Shiraz University
}

\section{Article history:}

Received date: 12 October, 2019

Review date: 03 December 2019

Accepted date:25 December 2019

\section{Keywords:}

Quality of fruit, Kinnow tangerine,

Olive oil, Aloe Vera, Wax

\begin{abstract}
Citrus is one of the perishable products in agriculture being destroyed with high costs after production. Thus, using treatments to avoid perishing is of great importance. Kinnow tangerines were kept in cold warehouse in accordance to completely randomized factorial design in four replications and four treatments of wax (commercial wax, laboratory wax, aloe Vera gel and olive oil). After two or fourth months of keeping, weight reduction, $\mathrm{pH}$, acidity, TSS and vitamin $C$ were evaluated. The results showed that the quality of fruits had significant difference over time as this reduced the quality of fruits. The treatment with aloe Vera gel with the highest weight reduction showed significant difference compared to the other wax treatments. The fruits treated with commercial wax had low vitamin $C$ compared to other treatments. The average pressure of skin in commercial wax and laboratory wax was higher than that of other treatments. However, in terms of the flesh to skin ratio, water reduction of flesh and skin, TSS value, PH and flavor, there was no significant difference among four treatments. The results of the test showed that four types of treatments reduced fruit weight considerably without having any harmful effect on the flavor and the internal and external qualities of the fruit were kept well for a long time.
\end{abstract}

Please cite this article as: Kalantari MR,. Rahemi M. 2020. The effect of aloe Vera gel, olive oil and wax on some quantitative and qualitative attributes of Kinnow tangerine in cold store. SRPH Journal of Fundamental Sciences and Technology, 2(1), 14-21

\section{Introduction:}

The losses of perishable products are of great importance in agriculture and this is occurred for various reasons including lack of consideration of time, harvesting rules, transportation and keeping these products. According to the estimations, the waste of citrus is $28-30 \%$ (Shahbake et al, 2002). If this value is assumed as $30 \%$, about 1.1 million ton citrus is lost after production with high cost. According to a report by ministry of agriculture in Iran, the losses of citrus are 451 thousands ton in harvest and handing, 144 thousands ton in cold storage and 313 thousands ton in transportation operation. As plants continue transpiration and respiration after harvesting, they lose water and food in some reactions and we have perishable products and this increases the costs. Now, the experts recommend emphasizing on shelf-life and storage instead of increasing production and reduce the losses during transportation to sell high quality fruits to the users (Rahemi , 2010).

For some years, chemical materials were used to control the post-harvesting diseases and losses (Trout et all, 1963) . In a study, Aloe Vera extract showed an inhibiting effect on the growth of $F$. oxysporum, $R$, Solani, C. cocco des fungi. This material is used to increase shelf-life of fruits (Dhillion et al ,1976).

Aloe is used as moisturizer and wound healing material with polysaccharide compound. The most important difference is Glucomannan as polysaccharides and as lactose and Uronic acid as pent saccharide (Mohammadi, 1994) . Oils and plant extracts are natural biological inhibitors affecting the activities of fungus.

A researcher (Garcia and Brenes, 2001) applied the effect of commercial oil to protect Candida albicans. Olive oil consists of oleic acid, linoleic acid and Palmitic acid and besides refreshing the fruit has anti-fungus effect (9). Evaporated wax has been used commercially in recent years.

These waxes are used with air nozzles and they have low water (Lacasse, 1986). 
As some local and foreign cultivars of citrus are harvested and sent to market simultaneously, the high variety of this product in market reduces its price in harvesting. By storing some of these fruits, we can increase its supply period and avoid losses in harvest season. The reduction of losses at any stage or any amount of harvest to consumption is a national movement and should be performed by researchers using new technologies and with implementation of research projects. As it was said, the purpose of this study is evaluation of the effects of treatment with wax, olive oil and aloe Vera gel on shelf-life and reduction of losses of Kinnow tangerine.

\section{Materials and Methods:}

This study was conducted in March 2011 in Agriculture School of Shiraz University. Kinnow tangerine is harvested from a commercial garden in Darab, Iran. The fruits are isolated and those damaged are eliminated. 160 fruits are selected randomly and are divided into two 80 groups and then each of two groups are used in 20 groups with four different treatments of olive oil, aloe Vera gel, commercial wax (resin, XEDASOL French, Arabi trade) and the laboratory wax (Sodium hydroxide $6 \mathrm{~g}$, ethanol amine $20 \mathrm{~g}$, stearic acid $42 \mathrm{~g}$, solid paraffin $165 \mathrm{~g}$, wax $55 \mathrm{~g}$, Shellac $100 \mathrm{~g}$ and water $2000 \mathrm{~mL}$ ). The fruits are washed at first using water and some drops of dishwashing soap and then are dried on a wire net and then for thermal treatment, it is put at temperature $35^{\circ} \mathrm{C}$ for 24 hours. After thermal treatment, for each treatment there were four replications and for each replication, 5 fruits are considered. In wax treatment, the fruits are submerged for $1 \mathrm{~min}$ in emulsion of wax and then are dried on wire net. For treatment with aloe Vera gel, the leaves are washed using water and are put in sodium hypochlorite $2 \%$ for $30 \mathrm{~min}$ and are washed with distilled water and then the leaves are cut longitudinally and the front and back of leaves were opened and the samples are put in gel and then are dried on wire net. In olive oil treatment, the fruits are covered by olive oil. Five fruits are used for each treatment and in control group, the fruits are used in plastic bags of poly ethylene with 16 holes and are kept at cold store at the temperature $6^{\circ} \mathrm{C}$ and relative humidity $85 \%$ and at the end of the second and fourth month of shelf-life, the following factors are evaluated:

Quality of juice (vitamin C, acidity, pH, TSS), weight reduction of fruits, stiffness, flesh to skin ratio, flavor. To evaluate juice quality, juice was taken from the fruits of each treatment and replication with manual mixers. They juice was sieved with a thin fabric and was evaluated for the following measurements.

Vitamin C is measured using Indophenol titration (Brater , 2002).

Total acid: It is measured via titration based on Indicator method (Skinner J. 1997 and Suntorank et all, 2002)

TSS: it is measured by glucose meter (GHD, Japan).

$\mathrm{pH}$ : It is measured by $\mathrm{pH}$ meter Ionyzer model 801/digital.

Stiffness: It is measured using Pantrometer.

Flesh to skin ratio: A fruit of each treatment and replication is peeled by hand, the weight of flesh and skin is determined and by dividing the flesh weight by the weight of skin, flesh to skin ratio is determined.

Determine the reduction of water of skin and flesh: To measure relative reduction of skin and flesh of orange, a fruit of each treatment and replication is peeled, a part of both fruits is dried in oven $80^{\circ} \mathrm{C}$ to have constant weight. The juice of flesh and skin is defined as the percent of juice of skin and flesh. The flavor is evaluated using sensory evaluation using Kramer method (Keramer and Twigg, 1966).

After data collection, statistical analysis is performed. The results are analyzed using completely randomized factory test in four replications using SAS software and the means are evaluated via Duncan test at the level $5 \%$.

\section{Results:}

As the evaluation of the effects of different waxes is the aim of this test, the data were analyzed twice. First, at the end of two mounts, data were collected and analyzed to define the effects of different treatments at the end of storing. Second, at the end of fourth month of storing, the data are collected and analyzed again to define the effects of treatments in each period.

\section{a. The effect of treatments and time on fruit weight reduction}

The effect of different waxes on weight reduction of Kinnow tangerine is analyzed (table1). The results of weight reduction in each period and based on the type of wax are shown in Chart 1 . Weight reduction at the end of the second and fourth month showed that weight reduction percent at the end of fourth month was higher than the end of second month and there was a significant difference. The relationship between weight 
reduction and type of wax showed that only in aloe Vera wax, the highest weight reduction was observed but other waxes showed no significant difference. In all types of waxes, weight reduction is considerable and commercial wax has the lowest weight reduction (Chart 1).

\section{b. The effect of treatments and time on the flesh to skin ratio}

The mean of changes of flesh to skin ratio showed no significant difference between different waxes and by increasing storage time, there was no significant difference between the second and fourth month of shelf life.

\section{c. The effect of treatments and time on reduction of skin to flesh juice}

The results of percent of skin and flesh water of Kinnow tangerine with different treated waxes in two periods showed that there was a considerable increase in juice of skin over time but there was no significant difference among different types of waxes. There was no significant difference between different periods of storage among the different waxes.

\section{d. The effect of treatments and time on dissolved solids of fruit}

The results of percent of dissolved solids are shown in Chart 2 based on the type of treatment and time. TSS was reduced considerably and there was a significant difference between the end of second month and the end of fourth month (Chart 2).

\section{e. The effect of treatments and time on total acid of fruit}

The results of acidity are shown based on time and type of treatment in Chart 3. Although acidity of fruits is reduced considerably from the beginning to the end of period, there is a significant difference. However, type of treatment has no difference in acidity and there is no significant difference (Chart 3).

\section{f. The effect of treatments and time on $\mathrm{pH}$ of fruit}

The results of $\mathrm{pH}$ are shown in Chart 4. $\mathrm{PH}$ is increased from the beginning to the end of period and there is a significant difference between the first and second period. There is significant difference in $\mathrm{pH}$ among the different treatments (Chart 4).

\section{g. The effect of treatments and time on vitamin $\mathrm{C}$ (Ascorbic acid)}

The results of vitamin $\mathrm{C}$ in fruits are shown in Chart 5. There is a little reduction in vitamin $\mathrm{C}$ over time but there is no significant difference. Vitamin $\mathrm{C}$ of fruits treated with commercial wax has significant reduction compared to the treatment with olive oil and laboratory wax. In these two treatments, there is highest vitamin C (Chart 5).

\section{h. The effect of treatments and time on average pressure of fruit}

The results of average pressure of skin are shown in Chart 6 . There is a little increase in average pressure of tangerine skin over time but this difference is significant. The average pressure of tangerine skin in commercial wax treatments and laboratory wax is higher than that of two treatments with aloe Vera gel and olive oil and there is a significant difference (Chart 6).

\section{i. The effect of treatments and time on flavor of fruit}

The different treatments have no effect on flavor of fruits at the end of second and fourth months.

\section{Discussion}

The results of different treatments under similar shelf-life reduced the weight of fruits. The similar results (weight reduction) regarding waxing citrus and other fruits are shown in Cortez et al., Rapisard et al., Safizade and Zarei et al.

The weight of waxed fruits is reduced due to the reduction of transpiration, as transpiration and $\mathrm{CO} 2$ reduction in respiration process are the main causes of weight reduction. Ben Yuhusha (1985) computed that about $90 \%$ of total weight reduction was dedicated to transpiration. Thus, the waxes reduced transpiration considerably. The highest value of weight reduction is seen in fruits with aloe Vera wax. This weight reduction was significantly higher than that of other treatments and it was because Aloe Vera couldn't create a uniform layer and a broken layer was created and transpiration was performed by these holes. This conclusion is consistent with the study of Ben Yuhusha (1969). By morphological study, they showed that a new layer is created after waxing and it has holes.

In a study on rat large intestine showed that AloinB, A under anaerobic condition can be turned into Emodin anthrone and increase penetration of cellular wall and if such condition is created in fruits, weight reduction and reduction of juices covered with aloe Vera gel can be justified (Kavfman, 1961).

Aloe Vera gel with antioxidants as vitamin E,C is oxidated rapidly and it is mucilage feature of antrikinon of Aloe Vera gel and it is effective on weight reduction (Wells AW, 1973). None of the treatments led into bad flavor of fruits. No anaerobic condition is created in fruits and this conclusion is consistent with the study of Ibn Yuhusha (1985). He reported that a commercial wax (Tag) avoided transpiration without having any 
effect on taste. The increase of flesh to skin ratio at different periods showed that the majority of juice was lost from the fruit skin than its flesh. Regarding the flesh to skin ratio, the results are consistent with the study of Hawkins (1921) in Grapefruit, Trot et al, (1963) in orange and Ashengton Navel, Loud et al., (1963) regarding tangerine. The study of Ben Yuhusha (3) regarding the percent of skin and flesh juice confirmed these results. In addition, there was no significant difference between waxing treatments in flesh to skin ratio and skin and flesh present and it showed the effectiveness of similarity of waxes.

The highest value of dissolved solid was observed in some fruits covered with aloe Vera wax. It seems that this increase is due to water evaporation. This increased the concentration of dissolved solid in fruit. These results are consistent with the study of Dhillion et al., and Pekmezci (1983). The dissolved solid between the end of second and fourth months showed significant difference and at the end of fourth mount was reduced. The increase of respiration reduced TSS and is consistent with the study of Mitter et al., (2009).

During the shelf-life, total acid and $\mathrm{pH}$ between treatments with different waxes are similar and these results are consistent with the study of Safizade (1991) and Hossein Zarei (2005). Over time, total acid is reduced and there is a significant difference in two shelf-life periods and this reduction was natural under long-term keeping. By the increase of life of fruit, the acids are used in respiration in Krebs cycle as consistent with the study of Lee and Kader (2000).

During shelf-life, vitamin $\mathrm{C}$ was reduced. This reduction is not significant and it is due to using acids in respiration reaction and Krebs cycle as consistent with the study of Lee and Kader (2000). Vitamin C is reduced considerably in commercial wax compared to other waxes and it is similar with the results of study of Dhillion et al and Paredes-Lopez et al (1974).

\section{General conclusion and recommendation:}

The results of this test showed that four types of treatments reduced weight of fruit without changing the flavor to maintain the internal and external quality of fruit. This study had no control. It is better to perform a control study and compare the effects of waxes with the control group to achieve exact results. If we have different concentration of treatment, we can achieve the best concentration and it is effective in terms of costs reduction.

\section{References:}

Aranzazu Garcia, Manuel Brenes. (2001)."Improvement or phenolic compound content is virgin olive oil by using enzymes during malaxatin".Journal of food engineering 48;189-199.

Ben - yehoshua , 1985. Individual seal-packing of fruit and vegetables in plastic film-A new postharvest technique. Journal Horticultural Science, 20(1) :32-37

Brater M.D. The United States Pharmacopoeia (USP) 25 and National Formulary (NF) 20, Webcom Limited. Toronto. 2002; p. 163.

Cortez-LAB. ; Teruel-BJ. ; Leal, PA.\& Neves, Fiho-Lc. (2000). Postharvest evaluation of some characteristics of oranges stored under refrigeration and ambient conditions, Alimentaria, No:311:129132

Dhillion,B.S.,P.S.Bains, and J. S. Randhawa.1976.Studies on the storage of kinnow mandarins. Journal agricultural of Research, Vol.XIV, No.4 :434-438

Hawkins,L.A.1921.A physiological study of grape fruit ripending and storage. Journal Agricultural of Research, 22:263. ( cited by Lodh $\underline{e t}$ al. , 1963 )

Kavfman. J.(1961), Parsnips. Produce Marketny 4:25-26.

Keramer Kramer, A. Twigg, B.A. 1966. Quality control for the food industry. AVI Publishing Company. PP 541.

Lacasse,S.T.(1986).Waxing equipment and material .pp 114-116,in: New England Fruit Meetings (F.G.Anderson,ed.) The massashusette fruit Growers Association, Inc.P.O. Box 632,North Amhest.MA 01059.

Lee.s and A. kader, 2000, preharvest and postharvest factors influencing vitamin c content of horticultural crops, postharvest Biology and Technology, 20: 207-220

Lodh,S.B. ,S.De,S.K.Mukherjee, and A.N.Bose.1963.Storago of Mandarin Oranges.II.Effects of Hormones and Wax Coatings. Journal Food Science.28:519-524.

Mitter. F. G. G. Jr, J.R. Soneji and M. Mageswara Rao2009: Citrus Breeding. Springer Journal Science+Business (105-113). 
Mohammadi Gh.(1994).Aloe Vera. Jungle research institute. PP 13-15.

Paredes-Lopez,O.,E.Camargo-Rubio,and Y.Gallardo Navarro. 1974. Use of coatings of candelilla wax for the preservation of limes. Journal Science Food Agriculture.25:1207-1210.

Pekmezci, M.1983.Studies on the storage of lemon Fruits. Journal Acta Horticulture, 138:203-209

Rahemi, Majid, 2010,Postharvest, Shiraz University Press,Shiraz,(In Farsi)

Rapisarda, P.; Bellomo.SE.\& Intelisano-So.(2001). Storage temperature effects on blood orange fruit quality, Journal of Agricultural and Food chemistry. 49(7).

Safizadeh, M.R., 1991,The effect of wax coating on sweet lime,Shiraz University, Shiraz,(In Farsi)

Shahbake, M. A., Famil Momen, R.and Behmad H. 2002. Status report on the postharvest sector in west and central Asia sob Region. Postharvest workshop, (3-6 February, Cario- Egypt)

Skinner J. 1997, in: Microscale Chemistry; Experiments in Chemistry, Measuring the amount of vitamin C in fruit drinks. Journal Royal Society of Chemistry., p. 67 (cf. J. Chem. Ed. 69, A213-4, 1992).

Suntorank L, Gritsanapun W , Nilkamhank S, Paochom A. ,2002, Quantitatitation of vitamin C content in herbal juice using direct titration. Journal of pharmaceutical and Biomedical Analysis. 28: 849855

Trout, G. B. Tindale, and F. E. Huelin.1983. The storage of oranges with especial reference to locality, maturity, respiration and chemical composition. Journal Science Industrial Research, Australia, Pamplet No. 80. (cited by Lodh et al., 1963 )

Wells AW. (1973). "Postharvest wax-fungicide treatments of nectarins, peaches, and plums for reducing decay, reducing moisture loss, and enhancing external appearance". (Abstr .). u. s . dep. Agri. mark. Res . Rpt.981

Zarei, H. , Sharifani, M, Razavi, SE., Maghsodlou, Y.,2005, Evaluation of chemical and physical treatments on storage life of Tompson orange fruit, Journal of agricultural science and natural resources ,ISSN.12(1): 1028-3099 


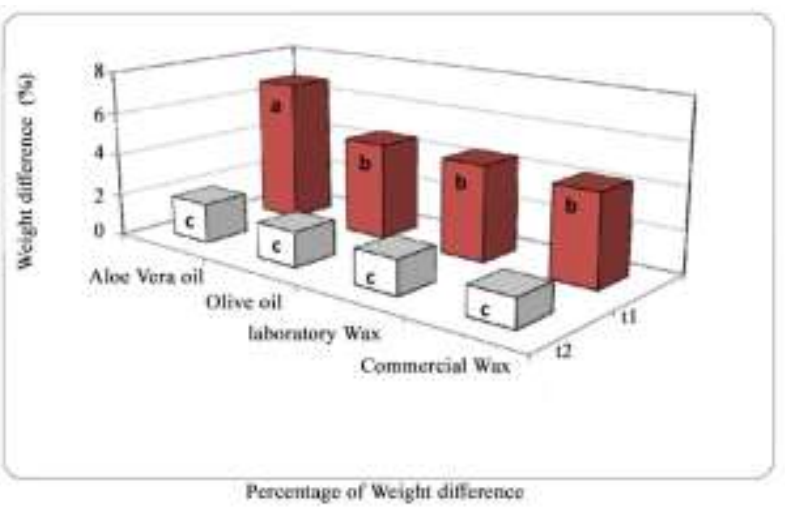

Figure 1: The effect of treatment and harvesting time on the fruit weight

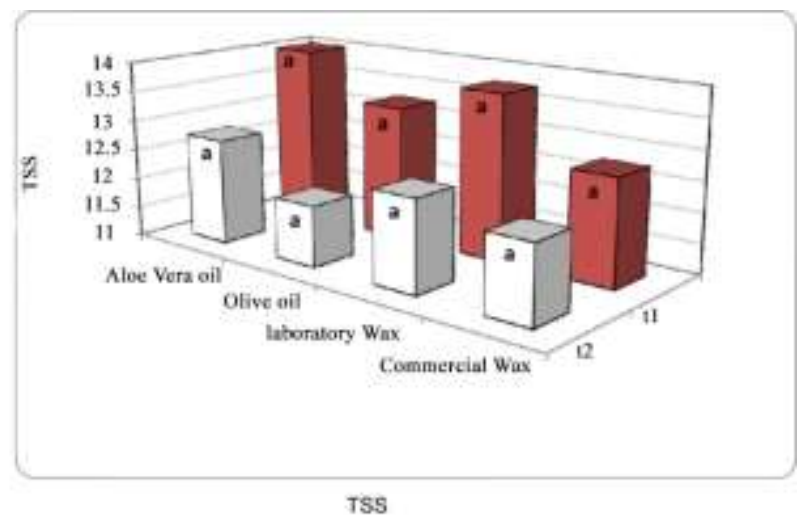

Figure 2: The effect of treatment and shelf-life period on the difference of mean of dissolved solid in fruit

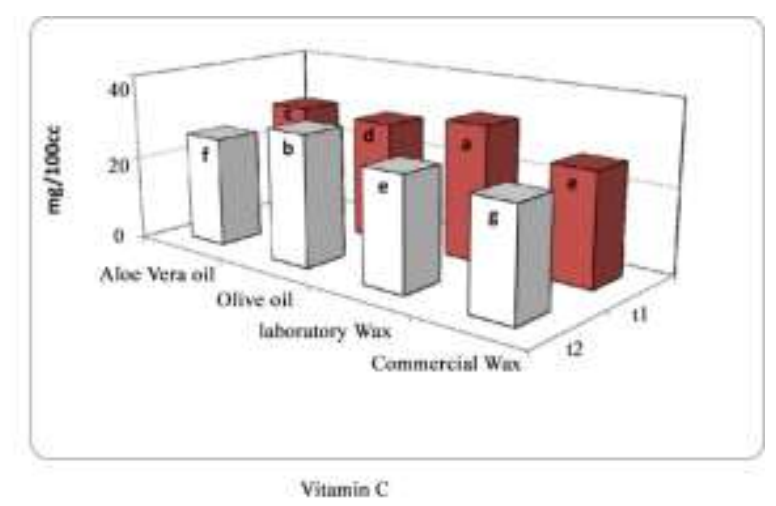

Figure 3: The effect of treatment and shelf-life period on the difference of mean of acidity in frui 


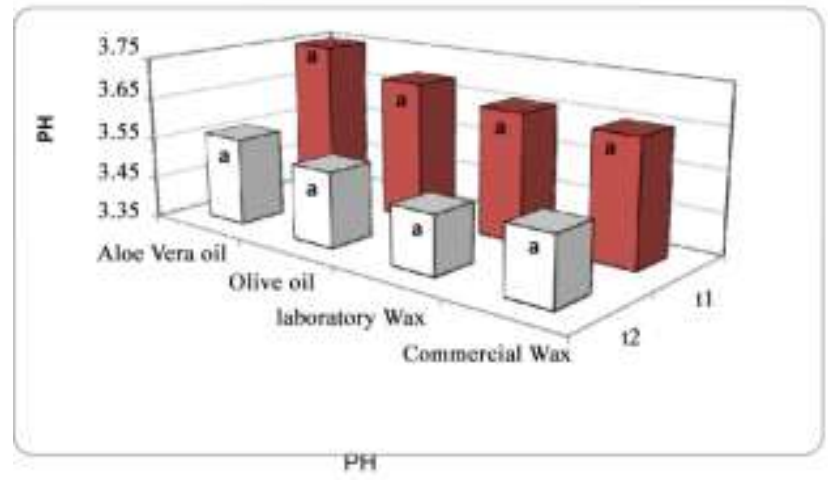

Figure 4: The effect of treatment and shelf-life period on the difference of mean of $\mathrm{pH}$ in fruit

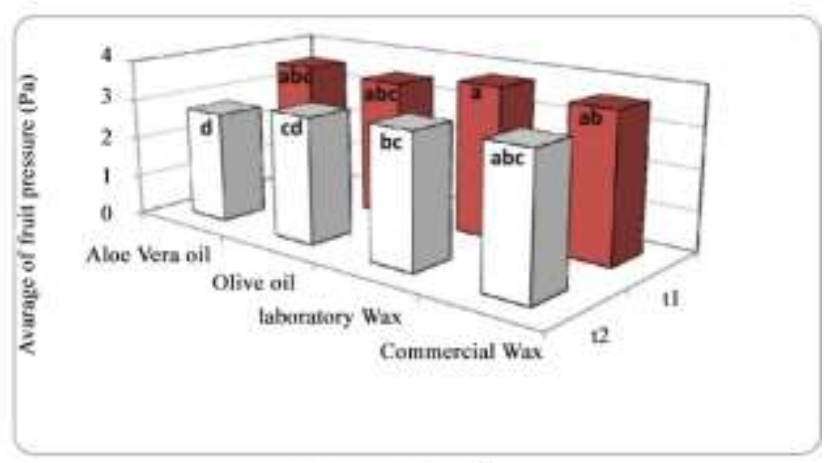

Pressure of Two Sides

Figure 5: The effect of treatment and shelf-life period on the difference of vitamin $\mathrm{C}$ in fruit 



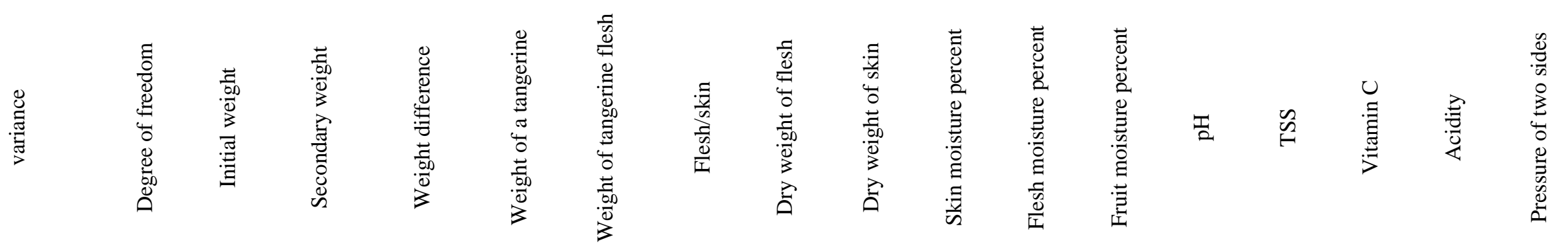

\begin{tabular}{|c|c|c|c|c|c|c|c|c|c|c|c|c|c|c|c|c|c|}
\hline Replication & 3 & 27.96 & 250 & 1.37 & 32.668 & 35.11 & 0.21 & 4.28 & 1.49 & 1.93 & 2.02 & 0.88 & 0.26 & 0.56 & 25.82 & 0.083 & 0.09 \\
\hline Wax & 4 & $3008 * *$ & $30115 * *$ & $12.91 * *$ & $1386^{*}$ & $445.19 *$ & 0.28 & $13.08^{*}$ & 14.61 & $30.0 *$ & 4.23 & 5.31 & 0.025 & 0.52 & 70.87 & 0.043 & 0.09 \\
\hline Time & 1 & 1932 & 1145 & $96.6^{* *}$ & 129.6 & 123.9 & 0.033 & 4.18 & 0.13 & 0.72 & 0.49 & 0.017 & $0.12 * *$ & 0.025 & 13.65 & $1.96 * *$ & 0.012 \\
\hline Time $\times$ wax & 4 & 3183 & 3323 & 2.48 & 838 & $381.8^{*}$ & 0.07 & 1.69 & 0.33 & 0.72 & 2.55 & 2.40 & 0.024 & 0.15 & 9.59 & 0.015 & 0.077 \\
\hline Error & 27 & 2396 & 2457 & 10.5 & 451 & 139.33 & 0.18 & 4.85 & 6.69 & 5.12 & 2.79 & 2.93 & 0.011 & 0.46 & 15.82 & 0.02 & 0.146 \\
\hline $\mathrm{Cv}$ & - & 6.27 & 6.64 & 23.17 & 14.79 & 11.75 & 17.75 & 16.65 & 22.95 & 3.09 & 1.93 & 2.06 & 2.83 & 0.47 & 7.99 & 13.22 & 12.76 \\
\hline
\end{tabular}

